\title{
Dietary conjugated linoleic acid differentially alters fatty acid composition and increases conjugated linoleic acid content in porcine adipose tissue
}

\author{
Ewa Ostrowska ${ }^{1}$, Reg F. Cross ${ }^{2}$, Morley Muralitharan ${ }^{3}$, Dale E. Bauman ${ }^{4}$ and \\ Frank R. Dunshea ${ }^{1,3 *}$ \\ ${ }^{1}$ Department of Primary Industries, 600 Sneydes Rd, Werribee, VIC 3030, Australia \\ ${ }^{2}$ Swinburne University of Technology, Hawthorn, VIC 3122, Australia \\ ${ }^{3}$ Deakin University, Geelong, VIC, Australia \\ ${ }^{4}$ Cornell University, Ithaca, NY 14853, USA
}

(Received 6 February 2003 - Revised 23 June 2003 - Accepted 21 July 2003)

\begin{abstract}
Conjugated linoleic acids (CLA) have been shown to decrease body fat content in pigs. It is possible that feeding pigs diets rich in CLA may increase carcass lipid CLA to levels that could provide health benefits when included as a part of a healthy diet. Therefore, the aim of the present study was to determine whether dietary CLA supplementation has any effect on the fatty acid composition of subcutaneous and intramuscular adipose tissue in pigs. Thirty-five female cross bred (Large White $\times$ Landrace) pigs (initial weight $57 \cdot 2 \mathrm{~kg}$ and initial P2 back fat $11.5 \mathrm{~mm}$ ) were used in the present study. Pigs were housed individually and randomly allocated to one of six dietary treatments $(0 \cdot 00,1 \cdot 25,2 \cdot 50,5 \cdot 00,7 \cdot 50$ and $10 \cdot 00 \mathrm{~g}$ CLA55 (55 g CLA isomers $/ 100 \mathrm{~g}$ total fatty acids; Natural Lipids Ltd, Hovdebygda, Norway)/kg) and fed their respective diets for 8 weeks. Twelve CLA isomers in the diet and in pig tissue lipids were separated by Ag ${ }^{+}-\mathrm{HPLC}$. CLA was incorporated at fivefold higher levels in subcutaneous fat as compared with intramuscular fat and in a dose-dependant manner. Overall, the transfer efficiency of CLA was maximized at $5.00 \mathrm{~g}$ CLA55/kg. However, there was clear selectivity in the uptake or incorporation of cis,trans-9,11 isomer over the trans,cis-10,12 isomer. In general, CLA supplementation produced significant changes in skeletal muscle and adipose tissue fatty acid composition, indicating that dietary CLA had a potent affect on lipid transport and metabolism in vivo. Significant increases in myristic, palmitic and palmitoleic acids and a reduction in arachidonic acid were observed, suggesting an alteration in activity of $\Delta^{5}-, \Delta^{6}$ - and $\Delta^{9}$-desaturases in pig adipose tissue. In conclusion, feeding pigs diets supplemented with CLA increases carcass lipid CLA, but also results in changes in the fatty acid profile in pig fat that could potentially outweigh the benefits of CLA.
\end{abstract}

Conjugated linoleic acid: Fatty acids: Pigs

With the increasing awareness of the importance of healthy diet in cancer prevention, there is interest in the manipulation of animal products to meet consumer demands for functional foods (Jiménez-Colmenero, 2001). There is convincing evidence from rodent models and in vitro models of carcinogenesis indicating that conjugated linoleic acid (CLA) is a potent naturally occurring anti-carcinogen (Shultz et al. 1992; Ip et al. 1994; Parodi, 1994; Durgam \& Fernandes, 1997). Human clinical and epidemiological results are more equivocal, with one study showing an inverse association between dietary and serum CLA and risk of breast cancer, particularly in postmenopausal women (Aro et al. 2000), although this was not confirmed in another study (Voorrips et al. 2002). CLA is a mixture of positional and geometric isomers $(18: 2 n-6)$ of linoleic acid (cis-9,cis-12-octadecadienoic acid) with conjugated double bonds at positions
9,11-, 10,12- or 11,13- on the C-chain of linoleic acid. The most common form in human diets is cis-9, trans11 CLA and the major source is the consumption of fat in dairy products (Ritzenthaler et al. 2001). Based on animal results, it was estimated that consumption of a diet containing as little as $1 \mathrm{~g} \mathrm{CLA} / \mathrm{kg}$ dry diet is sufficient to significantly reduce the incidence of tumours (Ip et al. 1994). Unfortunately, with the increasing consumption of low-fat dairy products and consequently a reduced intake of dairy fat, the richest source of CLA, these levels are often not met. Therefore, development of CLA-fortified products may help to increase the intake of CLA in the human diet; clearly more clinical studies are required before recommendations on the optimum amount of CLA in the human diet can be made.

Meanwhile, the potential to increase the level of CLA in animal fats via CLA supplementation of animal diets is

\footnotetext{
Abbreviation: CLA, conjugated linoleic acid.

* Corresponding author: Associate Professor Frank R. Dunshea, fax +6139742 0400, email Frank.Dunshea@dpi.vic.gov.au
} 
being explored. Consumption of CLA-enriched animal products by human subjects could help to increase the CLA intake, since animal fat constitutes about $60 \%$ of the fat available for consumption in developed countries such as Australia (Anonymous, 2000). Dietary CLA has been shown to be readily incorporated into liver and muscle lipids of the laboratory animals (Chin et al. 1994; Park et al. 1995; Banni et al. 1996; Belury \& KempaSteczko, 1997), but the incorporation of CLA varied according to the amount present in the diet and the length of time of intake (Banni et al. 1996; Ip et al. 1996; Belury \& Kempa-Steczko, 1997). CLA supplementation has also been reported as modifying fatty acid composition in pig tissue (O'Quinn et al. 2000; Eggert et al. 2001; Ramsay et al. 2001; Joo et al. 2002). The current study is an extension of our previous report (Ostrowska et al. 2003), where the supplementation of commercially sourced CLA (consisting of a mixture of at least twelve CLA isomers) was shown to improve performance and carcass composition. The objective of the present study was to investigate the effect of CLA supplementation on the fatty acid composition of adipose tissue and intramuscular fat of pork.

\section{Experimental methods}

\section{Animals and sample collection}

All procedures involving animals were approved by the Victorian Institute of Animal Science Animal Ethics Committee (Anonymous, 1997). Thirty-five (Large White $X$ Landrace) pigs were used in the experiment. Five pigs were killed at the beginning of the experiment. The remaining thirty pigs were blocked according to the live weight $(57.2$ (SD 1.9) kg) and back-fat thickness (11.5 $(\mathrm{SD} 1.3) \mathrm{mm}$ ) and randomly allocated to one of six dietary treatments. The CLA used in the present study was prepared from sunflower oil and contained $55 \mathrm{~g}$ CLA isomers in non-esterified fatty acid form $/ 100 \mathrm{~g}$ total fatty acids (CLA55; Natural Lipids Ltd, Hovdebygda, Norway). The CLA concentrations for the six diets were $0.00,1.25$, $2.50,5.00,7.50$ or $10.00 \mathrm{~g}$ CLA55/kg diet or $0.00,0.70$, $1.40,2.75,4.10$ and $5.50 \mathrm{~g}$ total CLA $/ \mathrm{kg}$ diet. The CLA content of the supplement and diets was measured by HPLC as described later (Cross et al. 2000; Ostrowska et al. 2000).

The experimental diets were formulated to contain 14.3 MJ digestible energy, 9.3 $\mathrm{g}$ lysine and $175 \mathrm{~g}$ crude protein $(\mathrm{N} \times 6.25) / \mathrm{kg}$ air-dry diet, which was in excess of protein and lysine requirements for the class of pig used in the study (Dunshea et al. 1993). The detailed diet composition has been published elsewhere (Ostrowska et al. 2003). The amino acid content relative to lysine was kept in excess of the amino acid balance proposed as ideal by the Standing Committee on Agriculture (1987) to ensure that lysine was the first limiting amino acid. Diets were fed ad libitum for 8 weeks and unlimited access to water was provided via nipple drinkers. Pigs were housed individually to allow measurement of individual feed intake daily and live weight measurements weekly.
After 8 weeks, pigs were slaughtered at an average live weight of approximately $107 \mathrm{~kg}$ (Ostrowska et al. 2003). Two samples of adipose tissue were collected from the $\mathrm{P} 2$ site $(65 \mathrm{~mm}$ from the midline over the last rib): the inner layer (adjacent to longisimus thoracis muscle) of fat and the outer layer of fat $(5 \mathrm{~mm}$ beneath the skin) were collected immediately after slaughter. Samples of muscle tissue were also collected from longissimus thoracis at the $\mathrm{P} 2$ site. The samples were stored at $-80^{\circ} \mathrm{C}$ before being analysed for the fatty acid composition and CLA isomer profile.

\section{Sample preparation for fatty acid analysis}

Fat was extracted using a chloroform-methanol (2:1, v/v) method (Folch et al. 1957). Preparation of non-esterified CLA was carried out according to the procedure of $\mathrm{Ha}$ et al. (1989). For GC analysis, non-esterified fatty acids were derivatized into methyl esters using the $\mathrm{BF}_{3}$ method (Association of Official Analytical Chemists, 1995).

CLA were separated by HPLC using a ChromSpher 5 Lipids analytical $(4.6 \mathrm{~mm}$ internal diameter $\times 250 \mathrm{~mm}$, stainless steel, $5 \mu \mathrm{m}$ particle size) Ag-impregnated column (Chrompack, Bridgewater, NJ, USA). The column was protected by a $3.0 \mathrm{~mm}$ internal diameter $\times 10$ $\mathrm{mm}$ guard column containing the same stationary phase. HPLC analyses were performed with a Varian (Walnut Creek, CA, USA) isocratic solvent delivery system equipped with a 9012 pump, a Prostar 330 photodiode array detector (ProStar, Varian Inc, Palo Alto, CA, USA) and a Star Workstation (version 5.3 Star software; Varian Inc.). All absorbances were measured at $234 \mathrm{~nm}$. Samples were introduced via a Rheodyne (Cotati, CA, USA) 8125 injector fitted with a $5 \mu$ l injection loop. A Timberline (Eureka, OR, USA) column heater maintained the temperature at $30^{\circ} \mathrm{C}$ for all runs. Minimum tubing diameters and distances were used between the injector and detector. The conditions used for separation of CLA non-esterified fatty acids in pig tissue were glacial acetic acid $(25 \mathrm{ml} / \mathrm{l})$ and acetonitrile $(0.25 \mathrm{ml} / \mathrm{l})$ at a flow rate of $1 \mathrm{ml} / \mathrm{min}$.

GC analysis of fatty acid methyl esters was carried out with a 3400 Varian GC (Varian Inc.) fitted with a flame ionization detector. A HP-INNO Wax (Hewlett Packard, Palo Alto, CA, USA), polyethylene glycol fused silica capillary column $(60 \mathrm{~m} \times 0.32 \mathrm{~mm}$ (internal diameter), $0.25 \mu \mathrm{m}$ film thickness) was used with he as the carrier gas at a flow rate of $2 \mathrm{ml} / \mathrm{min}(81.36 \mathrm{kPa})$.

Lipid standard (Sigma-Aldrich Pty Ltd, Castle Hill, NSW, Australia) containing thirty-seven different fatty acid methyl esters was used to determine the best conditions for separating all fatty acids present. The lipid standard was then spiked with the $99 \%$ pure CLA standard (Sigma-Aldrich Pty Ltd) containing twelve isomers, to ensure there was minimal overlapping of the peaks with the remaining fatty acid methyl esters. The conditions chosen were as follows: injector temperature set at $250^{\circ} \mathrm{C}$, detector temperature at $250^{\circ} \mathrm{C}$ and oven temperature programmed into four progressive steps: step 1, $50^{\circ} \mathrm{C}$ held for $1 \mathrm{~min}$; step $2,50-100^{\circ} \mathrm{C}$ at $20^{\circ} \mathrm{C} / \mathrm{min}$ and held for $1 \mathrm{~min}$; step $3,100-180^{\circ} \mathrm{C}$ at $20^{\circ} \mathrm{C} / \mathrm{min}$ and held for $2 \mathrm{~min}$; step $3,180-195^{\circ} \mathrm{C}$ at $1^{\circ} \mathrm{C} / \mathrm{min}$ and held for 
$1 \mathrm{~min}$; step $4,195-230^{\circ} \mathrm{C}$ at $10^{\circ} \mathrm{C} / \mathrm{min}$ and held for $30 \mathrm{~min}$. The volume injected ranged from 1.0 to $3.0 \mu \mathrm{l}$. The CLA fatty acids and other fatty acid methyl ester peaks were identified by comparison with the retention time of the reference standard.

\section{Calculations and statistical analysis}

Transfer efficiencies of the CLA isomers into porcine tissue were calculated using the following formula:

$$
\begin{aligned}
& \text { transfer efficiency }(\%) \\
& =((\text { fin. CLA }- \text { init. CLA }) \\
& \left.\quad-\mathrm{T}_{0} \text { fin. CLA }-\mathrm{T}_{0} \text { init. CLA }\right) \\
& \quad \times / \text { total CLA mass consumed }) \times 100,
\end{aligned}
$$

where fin. CLA is the final CLA mass (g), init. CLA is the initial CLA mass $(\mathrm{g}), \mathrm{T}_{0}$ fin. CLA is the final CLA mass $(\mathrm{g})$ in the control group of pigs and $\mathrm{T}_{0}$ init. CLA is the initial CLA mass $(\mathrm{g})$ in the control group of pigs.

One assumption in the estimations of transfer efficiencies was that the initial intramuscular fat content was a uniform value of $1.5 \%$ body weight. This was based on the analysis performed on the five pigs that were killed at the beginning of the experiment. The estimations of the initial fat and lean contents for the individual pigs were obtained by the dual-energy $\mathrm{X}$-ray absorptiometry. The total intramuscular fat mass at the beginning of the experiment was calculated by multiplying the initial intramuscular \% fat by dual-energy X-ray absorptiometry estimation of the total lean content for every pig (Ostrowska et al. 2003). The initial subcutaneous fat content was assumed to be the difference between the estimation of initial fat content by dual-energy $\mathrm{X}$-ray absorptiometry and the estimation of the initial intramuscular fat content. The subcutaneous CLA content at the beginning of the experiment was assumed to be a sum of CLA found in the inner and the outer layers of fat, and equal to the amount found in the control group of pigs at the end of the experiment, multiplied by the initial content of total subcutaneous fat. Similarly, the initial intramuscular CLA contents were assumed to be equal to the amount found in the control group at the end of the experiment.

\section{Statistical analysis}

Data were analysed by ANOVA suitable for a doseresponse, with linear and quadratic effects determined. The model included replicate and CLA dose. In addition, comparisons were made between diets containing either none or added CLA. For these analyses, the model included block, replicate and CLA dose. All analyses were performed using GENSTAT for Windows, version 4.1 (Payne et al. 1993).

\section{Results}

Appropriate blocking ensured that there was no difference in live weight $(57.2 \mathrm{~kg}, P=0.76)$ or $\mathrm{P}_{2}(11.5 \mathrm{~mm}, P=0.20)$ back fat between the different dietary CLA groups at the commencement of the study. Effects of dietary CLA on growth performance have been presented elsewhere, but briefly, there was no effect of CLA on average daily gain, while there was a small improvement in the ratio feed:gain with dietary CLA supplementation (Ostrowska et al. 2003). Significantly linear dose-dependent reductions in fat mass were observed in the carcass at the end of the study (Ostrowska et al. 2003).

The isomer composition of the dietary CLA, which was analysed by $\mathrm{Ag}^{+}$-HPLC, is shown in Table 1 . Once CLA was mixed in the diet, both GC and $\mathrm{Ag}^{+}$-HPLC analyses were used to confirm the content of CLA. Table 2 shows the GC analysis of the fatty acid composition of the fats extracted from the diets. The chromatographic analysis of the fats extracted from the diets confirmed that the dietary CLA was present at the expected levels $(0.00,0.69$, $1.38,2.75,4.13$ and $5.50 \mathrm{~g} \mathrm{CLA} / \mathrm{kg}$ diet). However, the substitution of CLA with soyabean oil resulted in small differences in the fatty acid profile of the fats extracted from the diets (Table 2). For example, soyabean oil consisted of about $500 \mathrm{~g}$ linoleic acid $(18: 2) / \mathrm{kg}$ with $450 \mathrm{~g}$ commercial mixture of CLA55/kg. Hence, control diets were slightly higher in linoleic acid content as compared with diets supplemented with CLA. This was also the case for myristic $(14: 0)$, palmitic $(16: 0)$, stearic $(18: 0)$ and linolenic acids $(18: 3)$, whereas the concentration of $\gamma$-linoleic $(\gamma-18: 3)$ acid increased with the dietary CLA in the diet.

$\mathrm{Ag}^{+}$-HPLC analysis of the CLA isomer composition in the outer layer and inner layers of fat and intramuscular fat are presented in Tables 3, 4 and 5 respectively. Small amounts of CLA were detected in pigs fed the control diets, with the highest quantity present in the inner layer of fat $(1.73 \mathrm{mg} / \mathrm{g}$ fat $)$, followed by the outer layer $(0.68 \mathrm{mg} / \mathrm{g}$ fat $)$, and lowest in the intramuscular fat $(0.43 \mathrm{mg} / \mathrm{g}$ fat $)$. The concentration of CLA detected varied across different fat depots; however, in all cases the levels increased in a linear fashion with the increasing level of dietary CLA in the diet. The significant $(P<0.001)$ linear

Table 1. Distribution of non-esterified conjugated linoleic acid (CLA) isomers in the CLA fraction of the commercial preparation of CLA55*

\begin{tabular}{lc}
\hline CLA isomer & $\mathrm{g} / 100 \mathrm{~g}$ total CLA isomers \\
\hline cis, trans/trans, cis-11,13† & $18 \cdot 33$ \\
cis, trans/trans, cis-10,12† & $30 \cdot 45$ \\
cis, trans/trans, cis-9,11† & 24.53 \\
cis, trans/trans, cis-8,10† & $13 \cdot 83$ \\
trans, trans-11,13 & $0 \cdot 18$ \\
trans, trans-10,12 & $0 \cdot 44$ \\
trans, trans-9,11 & $2 \cdot 04$ \\
trans, trans-8,10 & $2 \cdot 90$ \\
cis, cis-11,13 & 0.82 \\
cis, cis-10,12 & $2 \cdot 64$ \\
cis, cis-9,11 & $3 \cdot 18$ \\
cis, cis-8,10 & $\mathrm{ND}$ \\
Total & $99 \cdot 35$ \\
\hline
\end{tabular}

ND, not detected.

* CLA nominally contained $55 \mathrm{~g}$ CLA isomers $/ 100 \mathrm{~g}$ total fatty acids (CLA55; Natural Lipids Ltd, Hovdebygda, Norway).

†The slash between geometric isomers (i.e. cis,trans/trans, cis) means that either or both of the two isomers could be present. 
Table 2. Fatty acid composition of the total lipids extracted from the diets fed to the pigs*

\begin{tabular}{|c|c|c|c|c|c|c|}
\hline \multirow[b]{2}{*}{ Fatty acid } & \multicolumn{6}{|c|}{$\mathrm{g} / 100 \mathrm{~g}$ total fatty acids } \\
\hline & Diet $1 \dagger$ & Diet $2 \dagger$ & Diet 3† & Diet 4† & Diet 5† & Diet 6† \\
\hline $14: 0$ & 0.58 & 0.56 & 0.54 & 0.53 & 0.51 & 0.50 \\
\hline $16: 0$ & 11.87 & $11 \cdot 25$ & $10 \cdot 87$ & $10 \cdot 68$ & $10 \cdot 19$ & 9.71 \\
\hline $18: 0$ & $12 \cdot 50$ & $12 \cdot 40$ & 11.97 & $11 \cdot 13$ & $10 \cdot 29$ & 9.45 \\
\hline $18: 1$ & 22.58 & 21.94 & $21 \cdot 22$ & $22 \cdot 57$ & 22.57 & 22.58 \\
\hline $18: 2 n-6$ & $45 \cdot 52$ & 44.58 & $42 \cdot 66$ & 40.48 & 37.73 & 34.98 \\
\hline$\Sigma n-6$ CLA & ND & 1.70 & 3.67 & 7.43 & 10.89 & 14.92 \\
\hline $18: 3 n-3$ & 4.95 & 4.79 & 4.62 & $4 \cdot 30$ & 3.97 & 3.65 \\
\hline$\gamma-18: 3 n-3$ & 0.15 & 0.19 & 0.21 & 0.67 & 0.93 & $1 \cdot 18$ \\
\hline $20: 0$ & 0.12 & 0.12 & 0.11 & 0.10 & 0.10 & 0.09 \\
\hline $22: 6 n-3$ & 0.27 & 0.26 & 0.25 & 0.23 & 0.23 & 0.20 \\
\hline
\end{tabular}

ND, not detected.

${ }^{*}$ Fats were extracted using chloroform-methanol (2:1, v/v) method (Folch et al. 1957); total fat extracted from the diets was 36 (SD 1.2) $\mathrm{g} / \mathrm{kg}$ diet.

†Diets 1-6 correspond to different dietary levels of CLA included in the diet: (g CLA/kg diet): diet 1 (control) 0.00 , diet 21.25 , diet 32.50 , diet 45.00 , diet 57.50 , diet 610.00 .

increase in the concentration was evident for all the individual isomers of CLA detected in pig tissues. In the inner layer of fat and at the highest level of CLA supplementation as much as $15.10 \mathrm{mg}$ total CLA was detected per $\mathrm{g}$ total lipids (Table 4). Slightly less CLA was detected in the outer layer of fat $(13.50 \mathrm{mg} / \mathrm{g}$ fat; Table 3$)$ and fivefold lower concentrations were detected in the intramuscular fat $(2.88 \mathrm{mg} / \mathrm{g}$ fat; Table 5). In terms of individual isomers of CLA, the cis,trans-9,11 isomer was most abundant in all three fat depots. At the highest level of dietary CLA supplementation, the levels were $5.51,5.63$ and $0.70 \mathrm{mg} / \mathrm{g}$ fat collected from outer layer, inner layer and intramuscular fats respectively (Tables 3, 4 and 5). In the trans,trans and cis,cis group of isomers, the 9,11 isomer was also most abundant in all three fat depots, followed by a 10,12 homo$\log$ (Tables 3, 4 and 5).

Approximately one-third $(29.28 \%)$ of the total dietary CLA consumed by the pigs was incorporated into carcass lipid (sum of intramuscular, the inner and the outer layers of fat; Table 6). The highest transfer efficiency value $(39.17 \%$ ) was recorded for the group of pigs fed the intermediate level of dietary CLA $(5.00 \mathrm{~g} / \mathrm{kg})$. The transfer efficiency of CLA into the intramuscular fat was maximized $(0.76 \%)$ at $7.50 \mathrm{~g} \mathrm{CLA} / \mathrm{kg}$ diet (Table 6). The distribution of CLA isomers isolated from the intramuscular fat appears similar to that found in the diet; however, the incorporation of some isomers was less than that of others (Table 6). The most evident difference was in the incorporation of the trans,cis-10,12 isomer, which was the most abundant isomer in the CLA mixture fed to the pigs, but the least efficiently incorporated isomer in the porcine tissue. For the individual isomers in the cis,trans region, the transfer efficiencies in the intramuscular fat were maximized at the dietary CLA level of $7.50 \mathrm{~g} / \mathrm{kg}$ $(1.18,0.36,0.94$ and $1.03 \%$ for cis,trans-11,13, -10,12, $-9,11$ and $-8,10$ isomers respectively).

The transfer efficiency of the dietary CLA was much greater $(P<0.001)$ in the subcutaneous fat, at $28.78 \%$ across all dietary levels of CLA compared with $0.50 \%$ in the intramuscular fat (Table 6). The incorporation of total CLA into adipose tissue was maximized at dietary CLA concentration of $5.00 \mathrm{~g} / \mathrm{kg}(38.42 \%)$ followed by $7.50 \mathrm{~g}$
CLA $/ \mathrm{kg}$ (37.58\%). The incorporation efficiencies estimated for the individual isomers (Table 6) show that the trans,cis - 10,12 isomer was the least abundant isomer found in the subcutaneous fat. Overall, $13.30 \%$ of this isomer was incorporated into subcutaneous fat. The cis,trans - 9,11 was the most efficiently incorporated isomer, with almost half $(46.40 \%)$ of the amount of this isomer fed to the pig being incorporated into the adipose tissue. The second most efficiently incorporated isomer was the trans,cis $-8,10(28.78 \%)$, followed by the cis,trans $-11,13$ isomer (20.81\%). The transfer efficiency of the cis,trans - 9,11 isomer was maximized at the dietary CLA level of $5.00 \mathrm{~g} / \mathrm{kg}(66.4 \%)$. The cis,trans $-8,10$ homolog was incorporated most efficiently at concentration of $7.50 \mathrm{~g}$ dietary CLA $/ \mathrm{kg}$ diet $(39.23 \%)$. The transfer efficiencies for the remaining two isomers in the cis,trans group were maximized $(29.72$ and $18.16 \%$ for cis,trans $-11,13$ and $-10,12$ respectively) at the highest level of supplementation.

The transfer efficiencies for total CLA and the individual isomers tended to increase significantly $(P<0.001)$ with the increasing dietary level of CLA. The lowest value of transfer efficiency was recorded at the dietary CLA concentration of $1.25 \mathrm{~g} / \mathrm{kg}(7.40 \%)$. This could be partially due to the assumptions made in regards to the levels of CLA found in the adipose tissue at the beginning of the experiment. Because the CLA isomer composition of pigs at the beginning of the experiment was not analysed, the value adopted in the calculations of the transfer efficiencies was the concentration found in the control group of pigs at the end of the experiment. The concentrations of CLA are anticipated to be higher in heavier pigs than younger pigs, since CLA is known to originate from dietary sources and its accumulation in tissue is time dependent. Hence, the transfer efficiencies are possibly slightly underestimated and the values calculated for the lowest level of dietary CLA tended to be most sensitive to this assumption; in some pigs, the transfer efficiency values resulted in negative values.

The GC results of the fatty acid profiles in adipose and muscle tissues are presented in Tables 7 and 8 . The distribution of fatty acids was clearly affected by dietary 


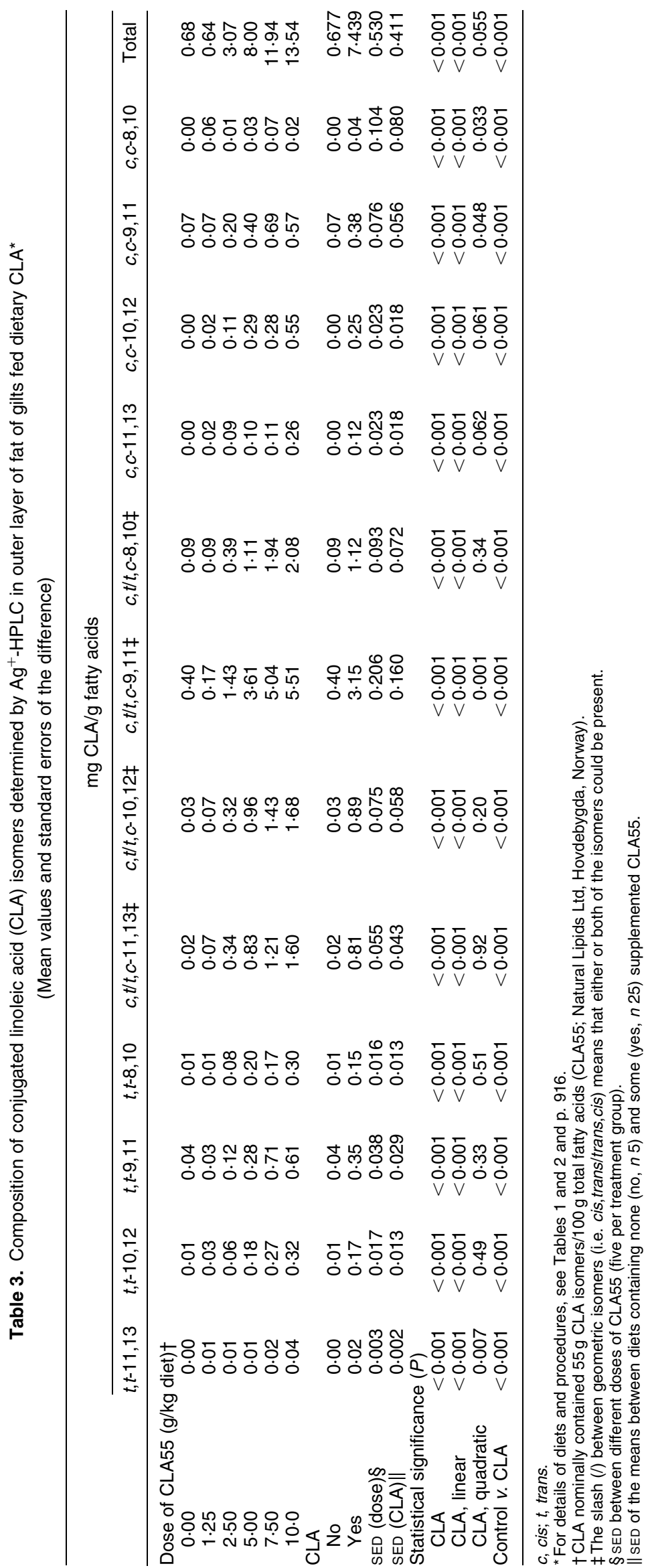




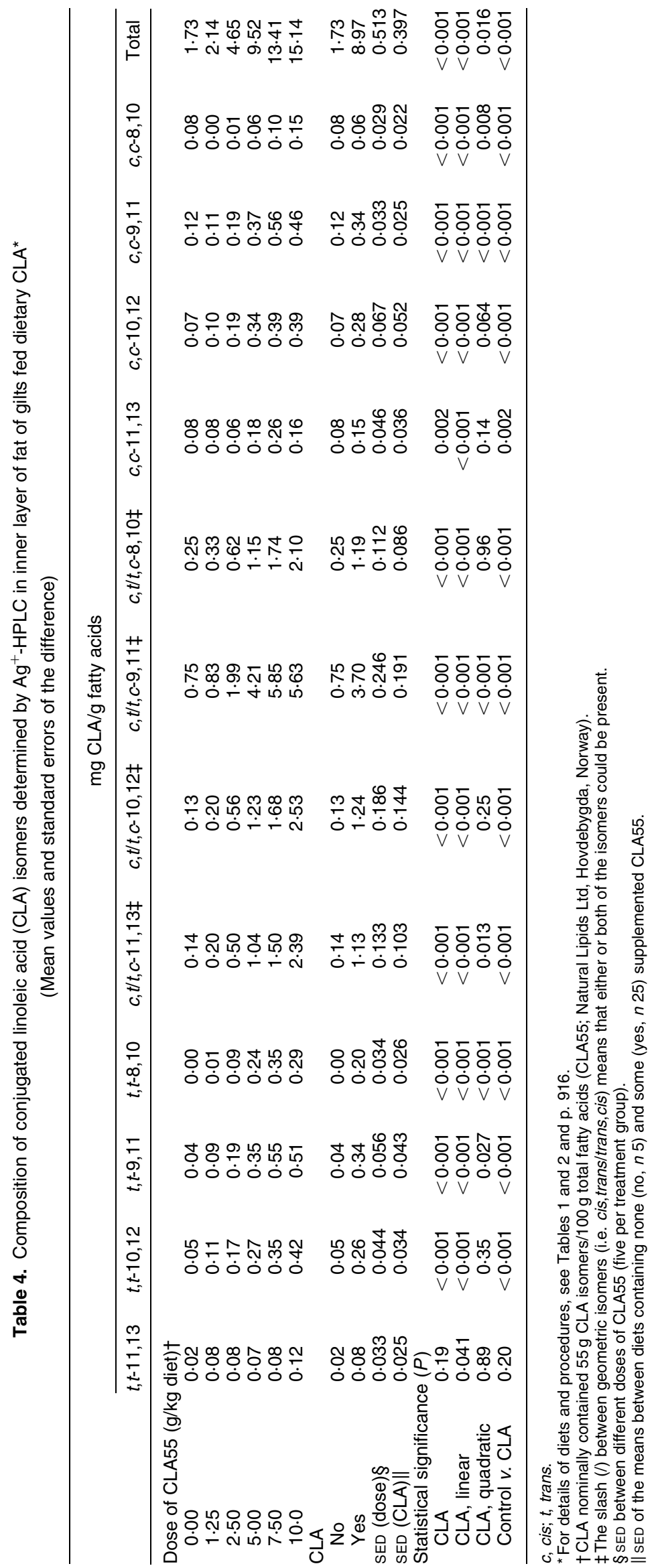




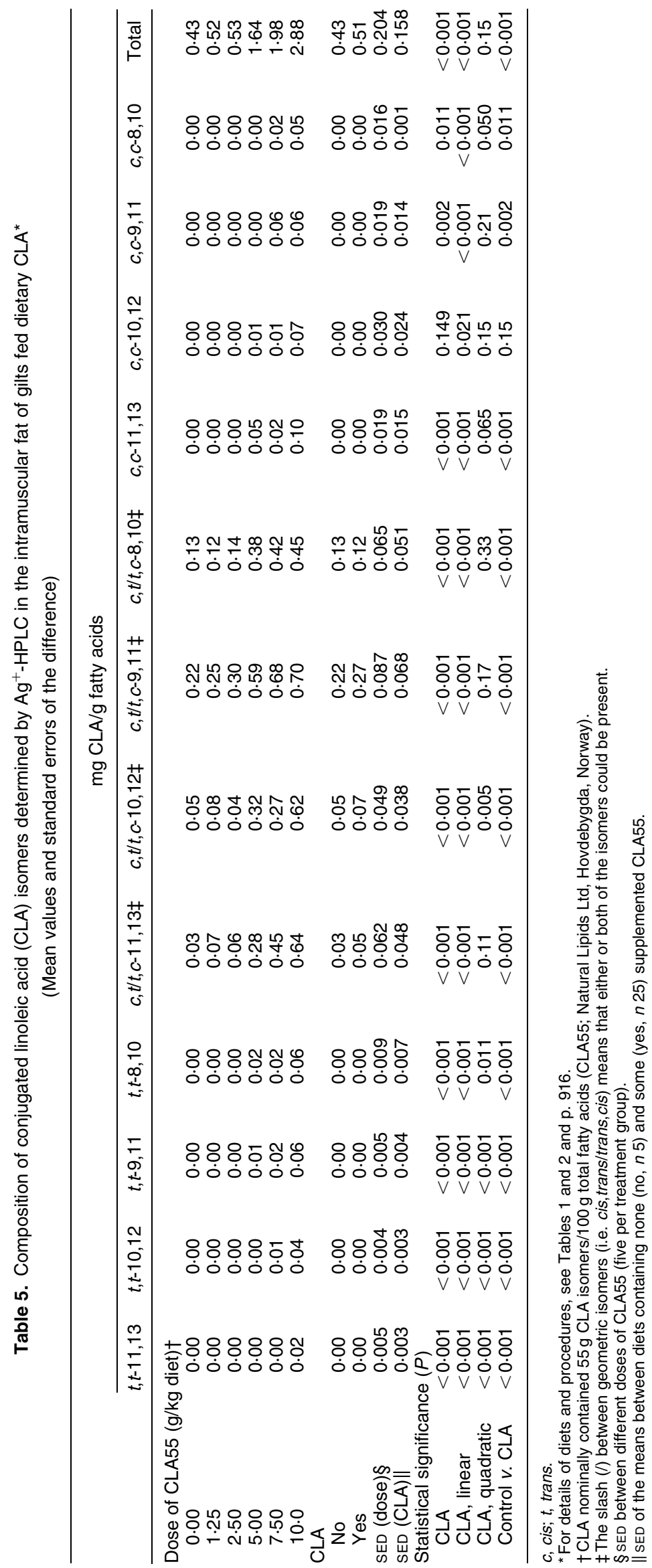




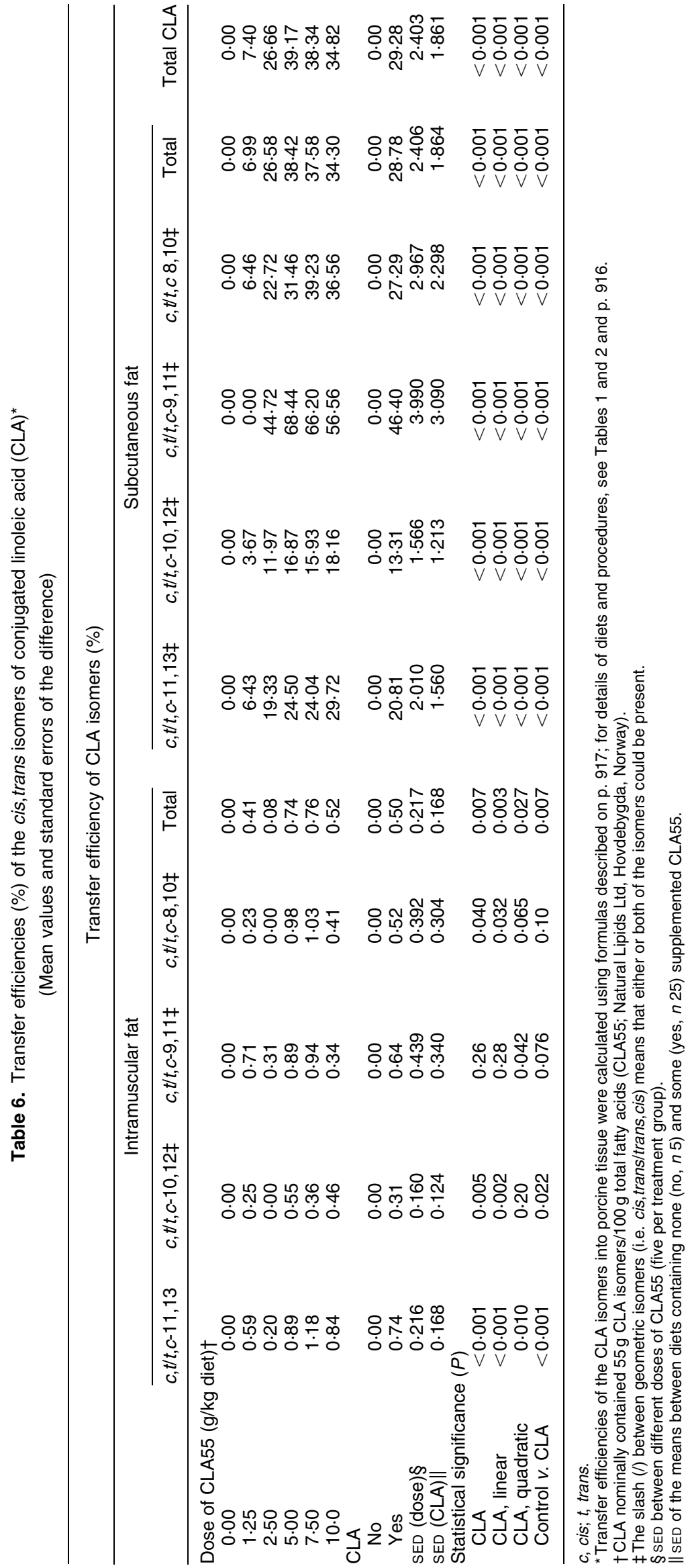


Dietary conjugated linoleic acid

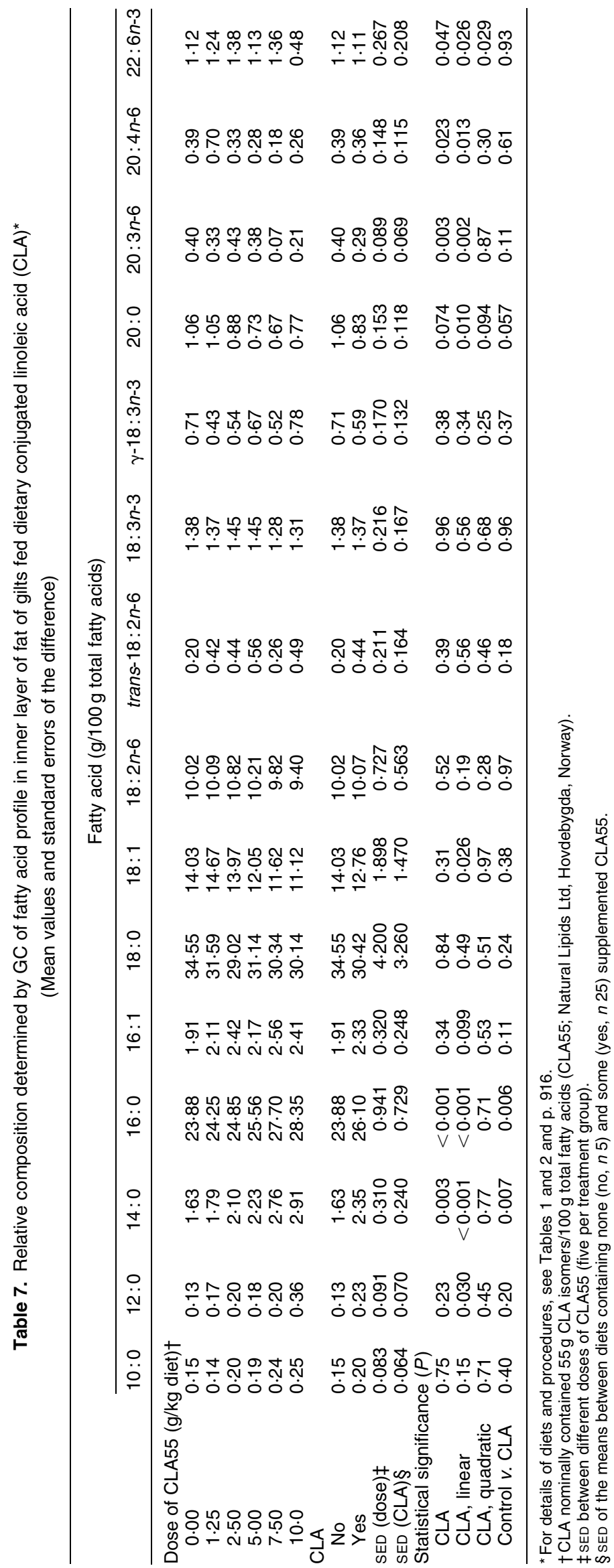




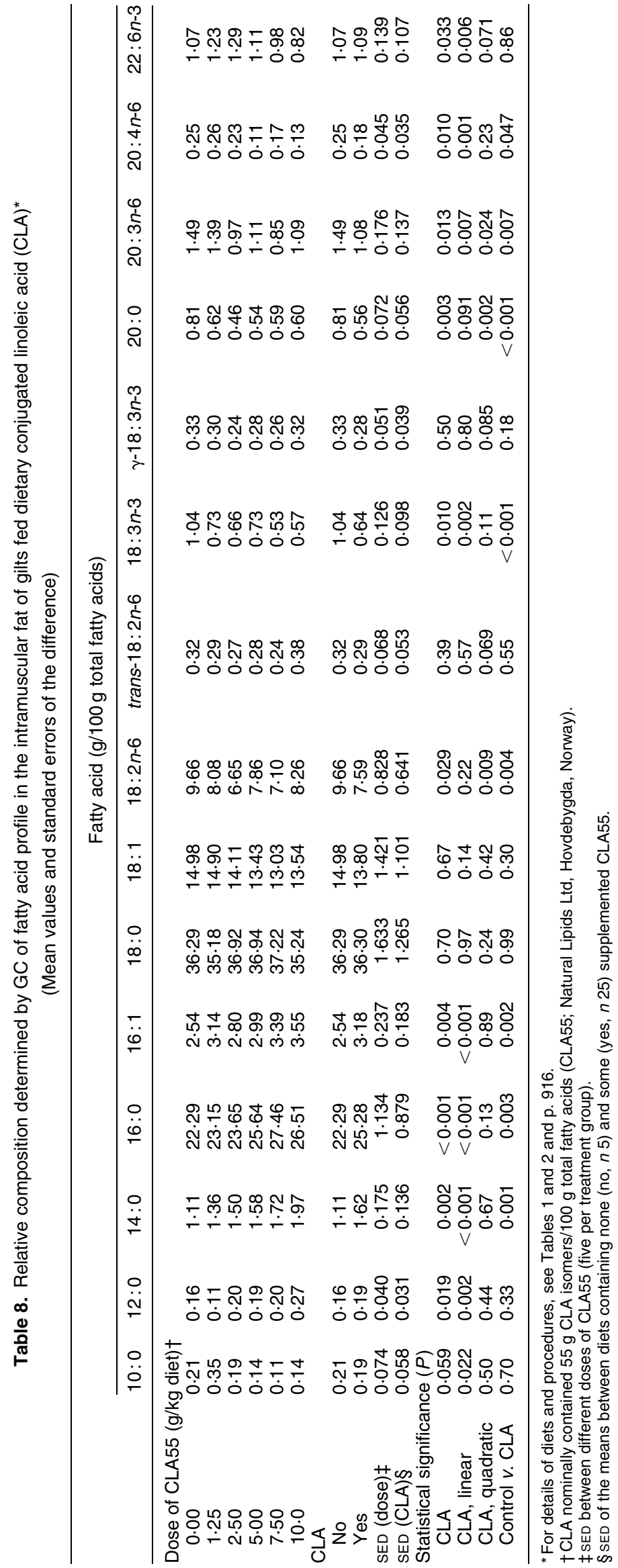


CLA. CLA reduced the levels of oleic $(18: 1)$, arachidic (20:0), eicosatrienoic $(20: 3)$ and arachidonic $(20: 4)$ acids in a linear fashion, while the content of decosahexaenoic acid (22:6) generally tended to be elevated at intermediate levels of dietary CLA. The relative proportions of the lauric (12:0), myristic (14:0), palmitic $(16: 0)$ and palmitoleic $(16: 1)$ acids were increased with the increasing concentration of CLA in the diet, despite their reduced levels in the diets supplemented with CLA (Table 2). The concentrations of linoleic acid $(18: 2)$ were similar in the inner layer of fat for different levels of dietary CLA supplementation, while they was reduced in a quadratic fashion in the intramuscular fat. The relative proportions of other fatty acids such as capric acid (10:0), stearic acid (18:0) and $\gamma$-linolenic acid $(18: 3)$ were also not affected by dietary CLA (Tables 7 and 8 ).

In the inner layer of fat (Table 7), CLA supplementation at lower concentrations of dietary CLA of 1.25, 2.50 and $5.00 \mathrm{~g} / \mathrm{kg}$ diet reduced the level of saturated fatty acids (by $3.90,6.80$ and $2 \cdot 20 \mathrm{~g} / 100 \mathrm{~g}$ total fatty acids respectively) and increased the level of unsaturated fatty acids (by $6 \cdot 50$, 9.30 and $2.30 \mathrm{~g} / 100 \mathrm{~g}$ total fatty acids respectively). At dietary CLA levels of 7.50 and $10.00 \mathrm{~g} / \mathrm{kg}$ the levels of saturated fatty acids were higher (by 1.00 and $2.20 \mathrm{~g} / 100 \mathrm{~g}$ total fatty acids) and unsaturated fatty acids were lower (by 1.70 and $3.80 \mathrm{~g} / 100 \mathrm{~g}$ total fatty acids) than for the control pigs. However, the difference between the CLA treatments and control pigs were not significant for both the saturated $(P=0.28)$ and unsaturated $(P=0 \cdot 17)$ fatty acids. The resulting ratio unsaturated:saturated fatty acids increased from 0.50 to 0.53 ; however, the differences were not significant $(P=0 \cdot 18)$. There was a trend $(P=0.06)$ towards linear reduction in proportion of monounsaturated (total of $16: 1$ and 18:1) fatty acids in pigs fed dietary CLA; however, the levels tended to be higher for lower concentrations of dietary CLA (15.94, $16.78,16.39,14.22,14.18$ and $13.53 \mathrm{~g} / 100 \mathrm{~g}$ total fatty acids for $0.00,1.25,2.50,5.00,7 \cdot 50$ and $10.00 \mathrm{~g} / \mathrm{kg}$ CLA respectively).

The increase in the proportion of saturated fats was more evident in the muscle tissue, where there was a significant linear increase $(P=0.006$; Table 8$)$. The highest proportion of saturated fatty acids was found in pigs fed $7.50 \mathrm{~g} \mathrm{CLA} / \mathrm{kg}$ diet: 67.47 compared with $61.14 \mathrm{~g} / 100 \mathrm{~g}$ total fatty acids in the control group. In general, CLA-fed pigs had 5.00 g more saturated fatty acids $/ 100 \mathrm{~g}$ total fatty acids than control pigs $(P=0.07)$. The proportion of unsaturated fatty acid tended to decrease quadratically $(P=0.07)$, with the lowest level $(27.58 \mathrm{~g} / 100 \mathrm{~g}$ total fatty acids) detected in pigs fed $7.50 \mathrm{~g} / \mathrm{kg}$ and the highest in the control group $(31.71 \mathrm{~g} / 100 \mathrm{~g}$ total fatty acids). This resulted in a quadratic response $(P=0.07)$, of the ratio unsaturated:saturated fatty acids.

In general, CLA-fed pigs had $13.50 \%$ lower ratio unsaturated: saturated fatty acids when compared with the control pigs $(P=0 \cdot 06)$. The proportion of monounsaturated $(16: 1$ and $18: 1)$ fatty acids remained unchanged $(17 \cdot 51$, $18.04,16.91,16.42,16.43$ and $17.09 \mathrm{~g} / 100 \mathrm{~g}$ total fatty acids for $0.00,1.25,2.50,5.00,7 \cdot 50$ and $10.00 \mathrm{~g} / \mathrm{kg}$ CLA respectively; $P=0.44$ ) in CLA-fed pigs.

\section{Discussion}

Incorporation of conjugated linoleic acid into tissues

The present results clearly indicate that supplemental dietary CLA was primarily incorporated into adipose tissue and to a lesser extent into intramuscular fat. Low concentrations of CLA, predominantly the most abundant naturally occurring isomer cis,trans-9,11 isomer (Parodi, 1994), were found in the corresponding tissues of control pigs. The CLA found in tissue from the control pigs probably originated from endogenous desaturation of trans-1118 : 1 (Gläser et al. 2002), since there was no CLA detected in the control diet. However, Chin et al. (1994) also reported that the large intestine of rodents had bacteria that had the ability to biohydrogenate linoleic acid to produce cis,trans-9,11 CLA and it is possible that this may occur in the relatively active hindgut of the pig.

The incorporation of individual and total isomers of CLA into adipose tissue increased proportionally with increasing level of dietary CLA, which is in agreement with earlier studies in mice (Belury \& Kempa-Steczko, 1997), rats (Chin et al. 1994; Sugano et al. 1997), hamsters (de Deckere et al. 1999) and pigs (Kramer et al. 1998). The difference between the total level of CLA found in the inner and outer layers of subcutaneous fat was very small but consistent across all levels of CLA supplementation, indicating a similar incorporation of CLA isomers into these two fat depots. However, fivefold lower levels of CLA were found in the intramuscular fat $(2.88 \mathrm{mg} / \mathrm{g}$ fat at the highest level of CLA supplementation) in the present study.

Although the concentration of individual isomers increased with the level of dietary CLA, there was obviously some selectivity in the uptake or incorporation of certain isomers, especially the cis,trans isomers. The calculated transfer efficiencies for the individual isomers showed that the cis,trans-9,11 isomer was most efficiently incorporated $(46.40 \%)$ in subcutaneous tissue, whereas in the intramuscular fat, the cis,trans-11,13 isomer was incorporated most efficiently $(0.74 \%)$. The preferential enrichment of cis,trans-9,11 is of particular value with respect to potential health benefits, as there is extensive evidence showing anti-cancer properties of this CLA isomer (for reviews, see Whigham et al. (2000) and Pariza et al. (2001)). The cis,trans-10,12 isomer, which is thought to be responsible for the reduction in lipid accretion and storage in growing animals (de Deckere et al. 1999; Park et al. 1999), was incorporated less efficiently, in both subcutaneous and intramuscular fat (13.31 and $0.31 \%$ respectively), than the remaining isomers in the trans,cis group (Table 6). The isomer selectivity for the transfer efficiencies found in the present study was in agreement with studies in rodents (Park et al. 1999), dairy cows (Chouinard et al. 1999a,b; Baumgard et al. 2001) and pigs (Kramer et al. 1998). In dairy cows, trans,cis-10,12 is incorporated into milk fat with about one-half the efficiency found for the cis,trans-9,11 isomer (Chouinard et al. 1999a,b). Kramer et al. (1998) examined the incorporation of commercial CLA in many of the tissue lipid classes of pigs and found that preferential incorporation of the cis,trans-9,11 isomer into liver 
phospholipids and of the cis,trans-11,13 isomer into heart lipids. In both liver and heart lipids, the relative proportions of trans,cis-10,12 and trans,cis-8,10 were significantly lower than that found in the diet (Kramer et al. 1998).

These findings imply that the levels of CLA can be increased in pig adipose tissue and intramuscular fat to levels similar to those reported in literature for dairy products (typically $2-24 \mathrm{mg} / \mathrm{g}$ fat). Thus, there is a potential to substantially increase the level of CLA, particularly the cis,trans-9,11 isomer, which is more readily incorporated into animal fats, through supplementing CLA into animal diets and consequently increase CLA intakes in human diets.

\section{Changes in fatty acid composition}

Dietary polyunsaturated fats (both $n-6$ and $n-3$ fatty acid families) are readily incorporated into porcine adipose tissue lipids in a dose-dependent manner (Fontanillas et al. 1997; Warnants et al. 1999) with a resultant decrease in monounsaturated fatty acids, but little effect on saturated fatty acid content (Bee et al. 1999). In the present study, diets were formulated to contain CLA and/or soyabean oil. Substitution of soyabean oil with various amounts of CLA resulted in dose-dependent changes in myristic, palimitic, stearic and linolenic acid concentrations in the diets (Table 2). Hence, some differences in the fatty acid profiles of the tissue lipids were anticipated due to differences in the fatty acid profile in the diets. Therefore, care should be taken in interpreting effects of CLA supplementation on changes in the profiles of other fatty acids.

Despite this caveat, it does appear that some changes in the fatty acid composition of porcine adipose tissue could be attributed to dietary CLA. For example, the concentrations of palmitoleic $(16: 1)$ and palmitic (16:0) acids in both intramuscular and subcutaneous fat increased in a linear fashion with increasing dietary CLA. This was clearly due to an effect of dietary CLA, since the level of dietary palmitic acid decreased with increasing dietary CLA. Palmitoleic acid was not detected in the diets; therefore, its origin was from desaturation of the respective saturated fatty acid, palmitic acid, which is in turn regulated by the fatty acyl-CoA $\Delta^{9}$-desaturase complex (Bee, 2000). The ratio palmitoleic: palmitic acid in the adipose tissue of the CLA supplemented pigs in general was not different from the control group, suggesting little effect of CLA on desaturation activity. When considering the fact that CLA supplementation results in dose-dependant reductions in fat deposition (Ostrowska et al. 1999, 2003), it appears that the increase in the concentration of these fatty acids is more likely to be due to the reduction in the fat deposition in CLA-fed pigs, than altered desaturase activity.

The $\Delta^{9}$-desaturase enzyme complex is also responsible for desaturation of stearic acid into oleic acid. In a present study, the concentration of stearic acid was not affected by dietary CLA despite the levels decreasing as the CLA increased in the diets, but a significant reduction in oleic acid was detected despite similar levels found in all the six diets. Similarly, Bee (2000) and Ramsay et al. (2001) reported a distinct shift toward lower oleic acid concentrations due to dietary CLA. This could be due to the depressed synthesis of oleic acid in the adipose tissue lipids, possibly due to decreasing stearoyl-CoA desaturase activity. Lee et al. (1998) provided evidence that CLA reduces the stearoyl coenzyme A desaturase mRNA abundance in rat liver by $45 \%$. Similarly, in dairy cows, dietary CLA influenced fatty acid composition of meat and milk through inhibition of desaturases at the level of transcription (Baumgard et al. 2002). In addition, Baumgard et al. (2001) and Peterson et al. (2002) have shown that the inhibition of desaturase is related to dose of CLA and at lower doses $(<7 \mathrm{~g} / \mathrm{d})$, where a $30 \%$ reduction in milk fat yield is evident, there is no effect of desaturase activity.

A significant linear reduction in arachidonic acid, in both the adipose tissue and intramuscular fat was detected in CLA-fed pigs. The arachidonic acid was not of dietary origin; therefore, it is likely that it was derived from desaturation of linoleic acid $(18: 2)$ or/and CLA to $\gamma$-linolenic acid $(18: 3)$ by $\Delta^{6}$-desaturase and elongation and subsequent desaturation of dihomo- $\gamma$-linolenic acid (20:3) by a $\Delta^{5}$-desaturase (Stone et al. 1979). Therefore, it is possible that CLA inhibits one or two of these specific desaturation steps, which are controlled by $\Delta^{6}-$ and $\Delta^{5}$ desaturases (Innis, 1993). This was also evident in the synthesis of $22: 6 n-3$, which also tended to be sensitive to changes in CLA concentration. The levels of 22:6 were above basal levels for pigs fed 1.25, 2.50 and $5.0 \mathrm{~g} \mathrm{CLA} /$ $\mathrm{kg}$ diet, but were lower at the higher doses of CLA. The content of $\gamma$-linolenic acid (18:3), an intermediate in the elongation and desaturation step of linoleic acid to arachidonic acid, tended to be reduced in the intramuscular fat of CLA-fed pigs, but the response tended to be quadratic in nature. Similarly, in mice and rats, CLA was incorporated into neutral lipids and phospholipids in a dose-response fashion at the expense of linoleate and arachidonate (Belury \& Kempa-Steczko, 1997). While CLA increased, arachidonate decreased significantly while linoleate decreased slightly. The $\Delta 9,11-18: 2$ isomer of linoleic acid was found to be a precursor for $\Delta 5,8,11,13-20: 4$ fatty acid (Belury \& Kempa-Steczko 1997). The enzymatic conversion of linoleate or CLA to $18: 3$ products by $\Delta^{6}$ desaturase was similar, suggesting that the enzyme did not utilize either CLA or linoleate preferentially as a substrate. However, it has not been determined whether CLA competes with linoleate for $\Delta^{6}$-desaturase (Belury \& Kempa-Steczko, 1997).

Overall, myristic, palmitic, palmitoleic and oleic acids were most sensitive to dietary CLA. The relative proportions of saturated fatty acids (16:0 and 18:0) were significantly increased in the intramuscular fat, but not the adipose tissue and some monounsaturated $(18: 1)$ and polyunsaturated fatty acids $(20: 3,20: 4$ and $22: 6)$ tended to be reduced by dietary CLA. Overall, saturated fatty acid content tended to be higher in CLA-fed pigs than control pigs and the proportion of unsaturated fatty acid tended to decrease quadratically, with the lowest level detected in pigs fed $7.50 \mathrm{~g} / \mathrm{kg}$ and the highest in the control group. The resulting increase in the ratio saturated: unsaturated 
fatty acids is unfavourable, since increased consumption of saturated fatty acids it is also associated with increased risk of CHD. The calculated index of atherogenicity (Ulbricht \& Southgate, 1991), which takes into consideration the CHD protective and promoting properties of fatty acids, was also negatively affected by CLA supplementation. Therefore, applying nutritional techniques to increase the polyunsaturated and monounsaturated fatty acid content of pork to compensate for the effects of CLA should be considered.

\section{Conclusion}

In conclusion, based on the analytical data from muscle fat and adipose tissues in the present study, all CLA isomers were incorporated into pig tissue in a dose-dependant manner. However, there appears to be selectivity in the uptake or incorporation of the cis,trans-9,11 isomer over the trans,cis-10,12 isomer. Taking into consideration the differences the biological activities between the isomers of CLA, it is important to assess the optimum levels of the individual isomers in foods and their health benefit. Furthermore, the increases in CLA concentrations in carcass lipids due to CLA supplementation were accompanied by less favourable changes in skeletal muscle and adipose tissue fatty acid composition. Therefore, the benefits of CLA-enriched animal products, possibly in combination with nutritional techniques to increase the polyunsaturated and monounsaturated fatty acid content to compensate for the effects of CLA, need to be evaluated in more detail. Finally, the assessment of the bioavailability and functional properties of newly available esterified CLA preparations containing fewer isomers need to be carried out.

\section{Acknowledgements}

The present study was supported by Australian Pork Limited. E. O. gratefully acknowledges a Swinburne University Postgraduate Research Award and an Australian Pork Limited Postgraduate 'Top-up' Scholarship.

\section{References}

Anonymous (1997) Australian Code of Practice for the Care and Use of Animals for Scientific Purposes, National Health and Medical Research, 6th ed., Melbourne, Victoria: CSIRO Publications.

Anonymous (2000) AgStats. Principal Agricultural Commodities. Preliminary 1998-99 (7111.0). ACT, Australia: Australian Bureau of Statistics.

Aro A, Mannisto S, Salminen I, Ovaskainen ML, Kataja V \& Uusitupa M (2000) Inverse association between dietary and serum conjugated linoleic acid and risk of breast cancer in postmenopausal women. Nutr Cancer 38, 151-157.

Association of Official Analytical Chemists (1995) Official Methods of Analysis of AOAC International: Method 969.33. Arlington, VA: AOAC.

Banni S, Carta G, Contini MS, et al. (1996) Characterisation of conjugated diene fatty acids in milk, dairy products, and lamb tissues. Nutr Biochem 7, 150-155.

Baumgard LH, Matitashvili E, Corl BA, Dwyer DA \&
Bauman DE (2002) trans-10,cis-12 CLA decreases lipogenic rates and expression of genes involved in milk lipid synthesis in dairy cows. J Dairy Sci 85, 2155-2163.

Baumgard LH, Sangster JK \& Bauman DE (2001) Milk fat synthesis is progressively reduced by increasing supplemental amounts of trans-10,cis-12 conjugated linoleic acid (CLA). J Nutr 131, 1764-1769.

Bee G (2000) Dietary conjugated linoleic acid consumption during pregnancy and lactation influences growth and tissue composition in weaned pigs. J Nutr 130, 2981-2989.

Bee G, Messikommer R \& Gebert S (1999) Dietary fats and energy levels differently affect tissue lipogenic enzyme activity in finishing pigs. Fett/Lipid 101, 336-342.

Belury MA \& Kempa-Steczko A (1997) Conjugated linoleic acid modulates hepatic lipid composition in mice. Lipids 32, 199-204.

Chin SF, Storkson JM, Albright KJ, Cook ME \& Pariza MW (1994) Conjugated linoleic acid is a growth factor for rats as shown by enhanced weight gain and improved feed efficiency. J Nutr 124, 2344-2349.

Chouinard PY, Corneau L, Barbano DM, Metzger LE \& Bauman DE (1999a) Conjugated linoleic acids alter milk fatty acid composition and inhibit milk fat synthesis in dairy cows. J Nutr 129, 1579-1584.

Chouinard PY, Corneau L, Saebo A \& Bauman DE (1999b) Milk yield and composition during abomasal infusion of conjugated linoleic acids in dairy cows. J Dairy Sci 82, 2737-2745.

Cross RF, Ostrowska E, Muralitharan M \& Dunshea FR (2000) Mixed mode retention and the use of competing acid for the $\mathrm{Ag}^{+}$-HPLC analysis of underivatized conjugated linoleic acids. J High Resolut Chromatogr 23, 317-323.

de Deckere EA, van Amelsvoort JM, McNeill GP \& Jones P (1999) Effects of conjugated linoleic acid (CLA) isomers on lipid levels and peroxisome proliferation in the hamster. Brit J Nutr 82, 309-317.

Dunshea FR, King RH, Campbell RG, Sainz RD \& Kim YS (1993) Interrelationships between sex and ractopamine on protein and lipid deposition in rapidly growing pigs. J Anim Sci 71, 2919-2930.

Durgam VR \& Fernandes G (1997) The growth inhibitory effect of conjugated linoleic acid on MCF-7 cells is related to estrogen response system. Cancer Lett 116, 121-130.

Eggert JM, Belury MA, Kempa-Steczko A, Mills SE \& Schinckel AP (2001) Effects of conjugated linoleic acid on the belly firmness and fatty acid composition of genetically lean pigs. J Anim Sci 79, 2866-2872.

Folch J, Lees M \& Sloane Stanley GH (1957) A simple method for the isolation and purification of total lipides from animal tissues. J Biol Chem 226, 497-509.

Fontanillas R, Barroeta A, Baucells MD \& Codony R (1997) Effect of feeding highly cis-monounsaturated, trans, or $n-3$ fats on lipid composition of muscle and adipose tissue of pigs. J Agric Food Chem 45, 3070-3075.

Gläser KR, Wenk C \& Scheeder MRL (2002) Effects of feeding pigs increasing levels of $\mathrm{C} 18: 1$ trans fatty acids on fatty acid composition of backfat and intramuscular fat as well as backfat firmness. Arch Anim Nutr 56, 117-130.

Ha YL, Grimm NK \& Pariza MW (1989) Newly recognized anticarcinogenic fatty acids: identification and quantification in natural and processed cheeses. J Agric Food Chem 37, $75-81$.

Innis SM (1993) Essential fatty acid requirements in human nutrition. Can J Physiol Pharmacol 71, 699-706.

Ip C, Briggs SP, Haegele AD, Thompson HJ, Storkson J \& Scimeca JA (1996) The efficacy of conjugated linoleic acid in mammary cancer prevention is independent of the level or type of fat in the diet. Carcinogenesis 17, 1045-1050. 
Ip C, Scimeca JA \& Thompson HJ (1994) Conjugated linoleic acid. A powerful anticarcinogen from animal fat sources. Cancer 74, 1050-1054.

Jiménez-Colmenero F, Carballo J \& Cofrades S (2001) Healthier meat and meat products: their role as functional foods. Meat Science 59, 5-13.

Joo ST, Lee JI, Ha YL \& Park GB (2002) Effects of dietary conjugated linoleic acid on fatty acid composition, lipid oxidation, color, and water-holding capacity of pork loin. $J$ Anim Sci 80, 108-112.

Kramer JK, Sehat N, Dugan ME, et al. (1998) Distributions of conjugated linoleic acid (CLA) isomers in tissue lipid classes of pigs fed a commercial CLA mixture determined by gas chromatography and silver ion-high-performance liquid chromatography. Lipids 33, 549-558.

Lee KN, Pariza MW \& Ntambi JM (1998) Conjugated linoleic acid decreases hepatic stearoyl-CoA desaturase mRNA expression. Biochem Biophysic Res Comm 248, 817-821.

O'Quinn PR, Andrews BS, Goodband RD, et al. (2000) Effects of modified tall oil and creatine monohydrate on growth performance, carcass characteristics, and meat quality of growing-finishing pigs. J Anim Sci 78, 2376-2382.

Ostrowska E, Dunshea FR, Muralitharan M \& Cross RF (2000) Comparison of silver-ion high-performance liquid chromatographic quantification of free and methylated conjugated linoleic acids. Lipids 35, 1147-1153.

Ostrowska E, Muralitharan M, Cross RF, Bauman DE \& Dunshea FR (1999) Dietary conjugated linoleic acids increase lean tissue and decrease fat deposition in growing pigs. J Nutr 129, 2037-2042.

Ostrowska E, Suster D, Leury BJ, et al. (2003) Conjugated linoleic acid decreases fat accretion in pigs: evaluation by dual-energy X-ray absorptiometry. Brit J Nutr 89, 219-229.

Park Y, Albright KJ, Liu W, Cook ME \& Pariza MW (1995) Dietary conjugated linoleic acid (CLA) reduces body fat content and isomers of CLA are incorporated into phospholipid fraction. In IFT Annual Meeting, p. 183. Madison, WI: University of Wisconsin, Department of Food Microbiology and Toxicology.

Park Y, Albright KJ, Storkson JM, Liu W, Cook ME \& Pariza MW (1999) Changes in body composition in mice during feeding and withdrawal of conjugated linoleic acid. Lipids 34, 243-248.

Payne RW, Lane PW \& Genstat 5 Committee (1993) Genstat 5 Reference Manual. Oxford: Oxford Science Publications.
Pariza MW, Park Y \& Cook ME (2001) The biologically active isomers of conjugated linoleic acid. Prog Lipid Res 40, 283-298.

Parodi PW (1994) Conjugated linoleic acid: an anticarcinogenic fatty acid present in milk. J Dairy Technol 49, 93-97.

Peterson DG, Baumgard LH \& Bauman DE (2002) Short communication: milk fat response to low doses of trans-10, cis-12 conjugated linoleic acid (CLA). J Dairy Sci 85, $1764-1766$.

Ramsay TG, Evock-Clover CM, Steele NC \& Azain MJ (2001) Dietary conjugated linoleic acid alters fatty acid composition of pig skeletal muscle and fat. J Anim Sci 79, 2152-2161.

Ritzenthaler KL, McGuire MK, Falen R, Shulthz TD, Dasgupta N \& McGuire MA (2001) Estimation of conjugated linoleic acid intake by written dietary assessment methodologies underestimates actual intake evaluated by food duplicate methodology. J Nutr 131, 1548-1554.

Standing Committee on Agriculture (1987) Feeding Standards for Australian Livestock. Pigs. Melbourne: CSIRO Publications.

Shultz TD, Chew BP \& Seaman WR (1992) Differential stimulatory and inhibitory responses of human MCF-7 breast cancer cells to linoleic acid and conjugated linoleic acid in culture. Anticancer Res 12, 2143-2145.

Stone KJ, Willis AL, Hart WM, Kirtland SJ, Kernoff PB \& McNicol GP (1979) The metabolism of dihomo-gamma-linolenic acid in man. Lipids 14, 174-180.

Sugano M, Tsujita A, Yamasaki M, Yamada K, Ikeda I \& Kritchevsky D (1997) Lymphatic recovery, tissue distribution, and metabolic effects of conjugated linoleic acid in rats. Nutr Biochem 8, 38-43.

Ulbricht TLV \& Southgate DAT (1991) Coronary heart disease: seven dietary factors. Lancet 338, 985-992.

Voorrips LE, Brants HAM, Kardinaal AFM, Hiddink GJ, van den Brandt PA \& Goldbohm RA (2002) Intake of conjugated linoleic acid, fat, and other fatty acids in relation to postmenopausal breast cancer: the Netherlands Cohort Study on diet and cancer. Am J Clin Nutr 76, 873-882.

Warnants N, Van Oeckel MJ \& Boucque CV (1999) Incorporation of dietary polyunsaturated fatty acids into pork fatty tissues. J Anim Sci 77, 2478-2490.

Whigham LD, Look ME \& Atkinson RL (2000) Conjugated linoleic acid: implications for human health. Pharmacol Res 42, 503-510. 